This item was submitted to Loughborough's Research Repository by the author.

Items in Figshare are protected by copyright, with all rights reserved, unless otherwise indicated.

\title{
Influence of process parameters on droplet size distribution in SPG membrane emulsification and stability of prepared emulsion droplets
}

PLEASE CITE THE PUBLISHED VERSION

http://dx.doi.org/10.1016/S0376-7388(03)00212-6

PUBLISHER

(C) Elsevier

VERSION

AM (Accepted Manuscript)

LICENCE

CC BY-NC-ND 4.0

\section{REPOSITORY RECORD}

Vladisavljevic, Goran T., and Helmar Schubert. 2012. "Influence of Process Parameters on Droplet Size Distribution in SPG Membrane Emulsification and Stability of Prepared Emulsion Droplets". figshare. https://hdl.handle.net/2134/10568. 
This item was submitted to Loughborough's Institutional Repository (https://dspace.lboro.ac.uk/) by the author and is made available under the following Creative Commons Licence conditions.

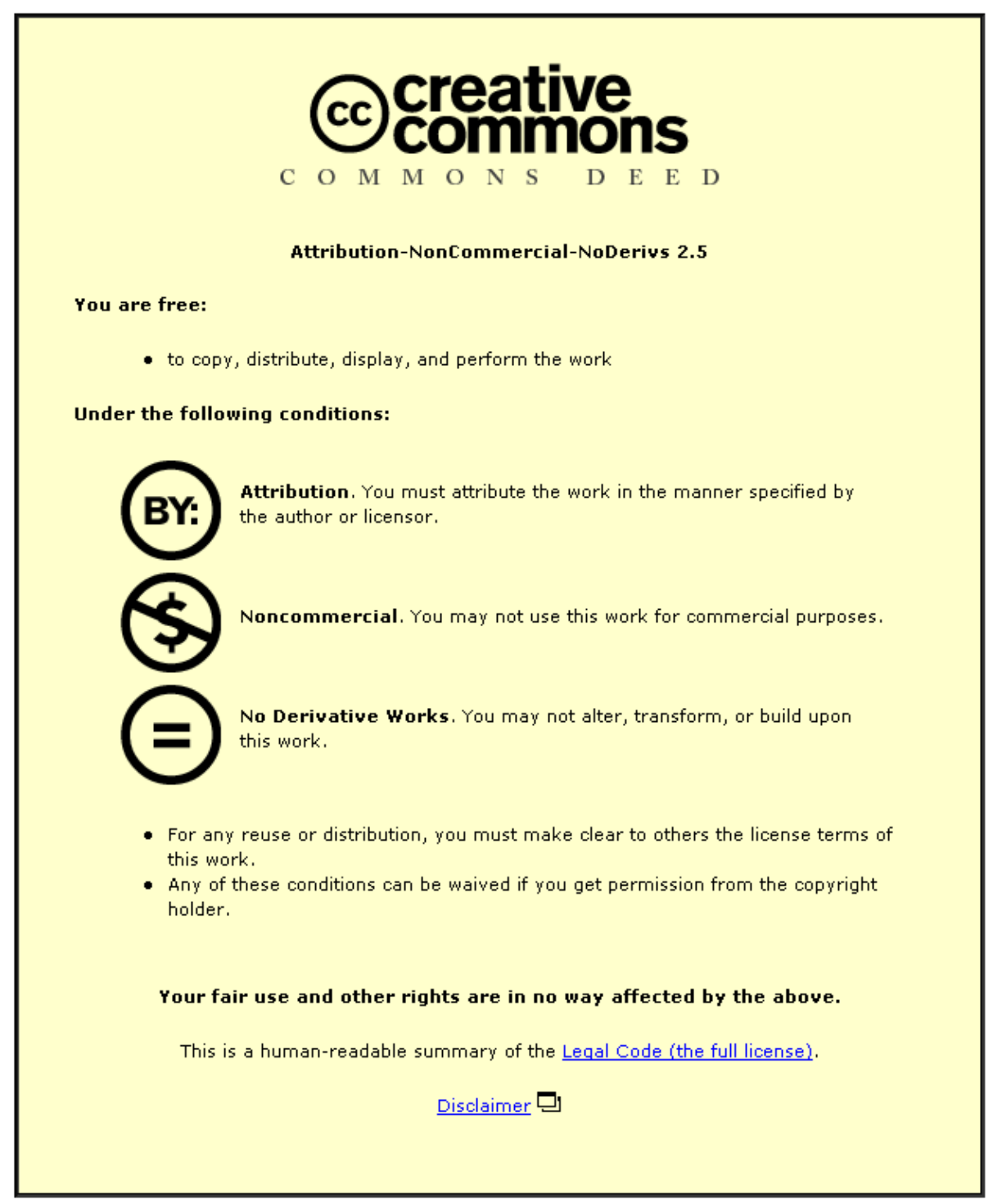

For the full text of this licence, please go to: http://creativecommons.org/licenses/by-nc-nd/2.5/ 


\section{Influence of process parameters on droplet size distribution in SPG membrane emulsification and stability of prepared emulsion droplets}

Goran T. Vladisavljevic ${ }^{\mathrm{a}^{*}}$, Helmar Schubert ${ }^{\mathrm{b}}$

${ }^{\mathrm{a}}$ Institute of Food Technology and Biochemistry, Faculty of Agriculture, University of Belgrade, P.O. Box 127, YU-11081 Belgrade-Zemun, Serbia, Serbia and Montenegro ${ }^{\mathrm{b}}$ Institute of Food Process Engineering, Faculty of Chemical Engineering, University of Karlsruhe (T.H.), Kaiserstrasse 12, D-76128 Karlsruhe, Germany

Abstract

SPG membranes were used to prepare monodispersed $\mathrm{O} / \mathrm{W}$ and $\mathrm{W} / \mathrm{O} / \mathrm{W}$ emulsions over a wide range of membrane wall shear stress $(0.37-40 \mathrm{~Pa})$, dispersed phase content (1-20 vol. \%) and transmembrane pressure. Although the most uniform droplets were prepared at the membrane wall shear stress of $30 \mathrm{~Pa}$, a monodispersed $\mathrm{O} / \mathrm{W}$ emulsion can be even obtained at the wall shear stress of $0.37 \mathrm{~Pa}$, corresponding to laminar flow regime of continuous phase inside the membrane tube. The minimum droplet size somewhat decreased with time, probably due to gradual activation of smaller pores. There was no significant difference in the size distribution curve of pure oil droplets of $\mathrm{O} / \mathrm{W}$ emulsions and W/O drops of W/O/W emulsions, if they were both prepared under the same conditions. No significant change in droplet size distribution of prepared O/W emulsions was observed during the storage time of up to 159 days.

*Corresponding author: Tel: +381 11615315 ext. 327; Fax: +381 11199711

e-mail address: gtvladis@afrodita.rcub.bg.ac.yu 
Keywords: Membrane emulsification; SPG membrane; Oil-in-water emulsions; Multiple emulsions; Dynamic interfacial tension.

\section{Introduction}

Membrane emulsification (ME) was developed by Nakashima et al. [1] for making monodispersed emulsions over a wide spectrum of mean droplet sizes, ranging from about $0.5 \mu \mathrm{m}$ to several tens of $\mu \mathrm{m}$. ME involves the permeation of pure dispersed phase through a porous membrane into moving continuous phase (direct ME) or the passage of previously prepared pre-emulsion through the membrane (premix ME [2]). In direct ME, small droplets are directly formed at the pore openings and detached from the membrane surface by the shear stress in continuous phase. In premix ME, large droplets are disrupted inside the pores by applying high dispersed phase flux. The emulsion droplets prepared by direct ME are more uniform, but on the account of much smaller membrane productivity. The work carried out in the field of ME was reviewed by Joscelyne and Trägårdh [3].

ME is a suitable technique for producing all types of single and multiple emulsions, including novel M/W (liquid metal-in-water) emulsions [4] and S/O/W (solids-in-oil-inwater) emulsions [5]. Nowadays, ME is mostly used for the small-scale production of highly advanced products (droplets or particles) with precisely controlled properties for electronics, medical care, functional food, analytical proposes, etc. These applications include the preparation of multiple emulsions for drug delivery systems (DDS), solder particles for surface mount technology [4], solid microcarriers for the encapsulation of a 
drug or nutrient using solid edible oil at an elevated temperature [6], silica powder for HPLC [7], monodispersed polymer microspheres, etc. The microspheres prepared by ME have been investigated as packings for analytical columns [8], carriers of enzymes [9], spacers for liquid crystal displays [7], and core particles for toner application [10]. A special type of DDS prepared by ME has been clinically tested for the arterial injection chemotherapy of liver cancer by Higashi et al. [11]. A promising large-scale application of ME in food industry is the production of low-calorie spreads [12], such as margarine (W/O emulsion) containing up to 75 vol. \% of dispersed water phase [7].

Shirasu porous glass (SPG) membrane developed by Nakashima and Shimizu [13] was used as a dispersion medium in the majority of the above mentioned applications. Under the same process conditions and for the same pore size and phase compositions, SPG membrane gives more uniform droplets than $\alpha-\mathrm{Al}_{2} \mathrm{O}_{3}$ membrane and seems to be even competitive with a microchannel plate [14]. A disadvantage of SPG membrane is a low dispersed phase flux through the membrane, which is necessary to obtain a narrow droplet size distribution by direct ME. In order to overcome this disadvantage, a new asymmetric type of porous glass membrane was recently developed and tested by Kukizaki et al. [15].

In spite of considerable amount of work carried out in the field of ME in the last decade, the influence of process parameters on droplet size distribution was not yet fully investigated. Furthermore, in some investigations only the mean droplet diameter was given as a parameter of distribution, although the width of droplet size distribution is a key emulsion property in the case of ME. The aim of this study is to investigate the influence of transmembrane pressure, wall shear stress and dispersed phase content, i.e. emulsification time on the shape of droplet size distribution curve of $\mathrm{O} / \mathrm{W}$ and $\mathrm{W} / \mathrm{O} / \mathrm{W}$ 
emulsions prepared using SPG membranes. In addition, the stability of $\mathrm{O} / \mathrm{W}$ emulsions has been studied over long periods of time, ranging up to 159 days. In all previous studies reported in the literature, the stability of $\mathrm{O} / \mathrm{W}$ emulsions prepared by ME has been investigated over limited storage time ranging from 24 hours [16] to 3-4 weeks [2, 17].

\section{Experimental}

\subsection{Materials}

O/W emulsions were prepared using rapeseed oil (Floreal GmbH, Germany) as the dispersed phase and 2 wt. \% Tween 80 (polyoxyethylene (20) sorbitan monooleate, Merck GmbH, Germany) dissolved in demineralized water as the continuous phase. The oil phase in W/O/W emulsions was 10 wt. \% polyglycerol polyricinoleate (PGPR 90, Danisco, Denmark) dissolved in rapeseed oil, the internal aqueous phase was phosphate buffer solution containing 5 wt. \% disodium hydrogen orthophosphate and potassium dihydrogen orthophosphate in the ratio of $4: 1$, and the external aqueous phase contained 2 wt. \% Tween 80 as the emulsifier and $0.5 \%$ sodium chloride as the osmotic additive.

\subsection{Membranes and membrane modules}

The SPG membrane tubes ( $8.7 \mathrm{~mm}$ inner diameter $\times 0.65 \mathrm{~mm}$ wall thickness) were supplied from SPG Technology Co., Ltd (Miyazaki, Japan). The mean pore size of the membrane determined by a Shimadzu model 9320 mercury porosimeter was in the range of 1.4-6.6 $\mu \mathrm{m}$. The membrane porosity determined by a picnometric method was in the range of 0.53-0.60, which was in excellent correspondence with the values obtained by mercury intrusion porosimetry. The effective membrane area was $31.3 \mathrm{~cm}^{2}$. 


\subsection{Experimental set-up and procedure}

O/W emulsions were prepared using a cross-flow ME system described elsewhere $[14,18]$. The experiments have been carried out over a wide range of membrane wall shear stress (0.37-40 Pa), dispersed phase content (up to 20 vol. \%) and transmembrane pressure (1.2-5.7 times greater than the capillary pressure).

W/O/W multiple emulsions were prepared by first making a fine W/O emulsion containing 10 vol. \% of the dispersed aqueous phase. This W/O emulsion was prepared by passing a pre-emulsion through the microfluidizer ${ }^{\circledR}$ (Microfluidics Corp., Newton, MA, USA) at an operating pressure of $110 \mathrm{MPa}$. The primary W/O emulsion with a mean droplet size of less than $0.2 \mu \mathrm{m}$ was than dispersed into the outer aqueous phase using a SPG membrane with the mean pore size of $5 \mu \mathrm{m}$ (Fig 1).

\subsection{Determination of mean droplet size and droplet size distribution}

Droplet size distribution for all samples was measured by a Coulter LS 230 light scattering particle size analyser using PIDS technology, which allowed the detection of droplets in the range of 0.04-2000 $\mu \mathrm{m}$. The mean droplet diameter was expressed as the mean Sauter diameter, $\mathrm{d}_{3,2}$. The width of droplet size distribution was expressed as a span of distribution: span $=\left(\mathrm{d}_{90}-\mathrm{d}_{10}\right) / \mathrm{d}_{50}$, where $\mathrm{d}_{\mathrm{x} 0}$ is the diameter corresponding to $\mathrm{x} 0$ vol. \% on a relative cumulative droplet size distribution curve.

\section{Results and discussion}

3.1. Dynamic interfacial tension of emulsifier (Tween 80) solutions 
The adsorption kinetics of emulsifier at oil-water interfaces plays an important role in ME. The slower the occupation of newly formed interfaces by the emulsifier, the higher the tendency of droplets to coalesce at the membrane surface. Fig. 2 shows the interfacial tension between the aqueous and oil phase as a function of time for Tween 80 at two different concentrations above CMC. Dynamic interfacial tension was measured by the bursting membrane method [19]. The distance between the bursting membrane and oil-water interface was $20 \mathrm{~mm}$ to exclude the effect of emulsifier diffusion to the interface on the measured interfacial tensions. According to Stang et al. [19], for small distances between the membrane and the interface of $6-23 \mathrm{~mm}$, the measured $\gamma$ values are independent on this distance, i.e. the system is not diffusion-controlled. As shown in Fig. 2, the more concentrated Tween 80 solution caused a faster decrease of the interfacial tension, approximately within 3 s to a value which was only $4 \%$ higher than the steady-state value of $8 \mathrm{mN} / \mathrm{m}$. However, the equilibrium interfacial tension was independent on the emulsifier concentration, because the both concentrations were well above critical micelle concentration of 33-45 mg/l. The typical droplet formation times in SPG membrane emulsification at the pressures slightly above the capillary pressure are $0.6-1.8 \mathrm{~s}$ [18]. Within this time interval, 2 wt. \% Tween 80 solution can decrease the interfacial tension to a substantially lower value than 0.2 wt.\% solution. Therefore, $2 \mathrm{wt}$. $\%$ emulsifier solution was choosen as a continuous aqueous phase in the subsequent experiments.

\subsection{Influence of process parameters on droplet size distribution}

The influence of transmembrane pressure on droplet size distribution for the 4.8- $\mu \mathrm{m}$ SPG membrane is shown in Fig. 3. Even at $\Delta \mathrm{p}_{\mathrm{tm}} / \mathrm{p}_{\text {cap }}=5.7$ corresponding to a dispersed 
phase flux of $77 \mathrm{l} \mathrm{m}^{-2} \mathrm{~h}^{-1}$ (Fig. 4) the span of droplet size distribution was still rather small (0.52), but nevertheless significantly larger than at $\Delta \mathrm{p}_{\mathrm{tm}} / \mathrm{p}_{\text {cap }}=2-3$. The formation of larger droplets with diameters between 22 and $34 \mu \mathrm{m}$ was the main reason for the broadening the droplet size distribution curve at the higher $\Delta \mathrm{p}_{\mathrm{tm}} / \mathrm{p}_{\text {cap }}$ values.

For the conditions given in Fig. 4, the dispersed phase flux $J_{d}$ was proportional to $\Delta \mathrm{p}_{\mathrm{tm}}{ }^{2.3}$, which was due to a higher proportion of active pores at the higher pressure. E.g., only $1.3-1.4 \%$ of the pores was simultaneously active at $\Delta \mathrm{p}_{\mathrm{tm}} / \mathrm{p}_{\mathrm{cap}}=1.1-1.9$ and $8.5 \%$ at $\Delta \mathrm{p}_{\mathrm{tm}} / \mathrm{p}_{\text {cap }}=5.7$. A linear relationship between $\mathrm{J}_{\mathrm{d}}$ and $\Delta \mathrm{p}_{\mathrm{tm}}$ is obtained only if the proportion of active pores is independent on pressure. The proportion of active pores was calculated from the dispersed phase/pure water flux ratio, using the model given in our previous study [18]. The direct microscopic observation of pore activation is possible only at very small dispersed phase fluxes and low wall shear stresses.

Abrahamse et al. [20] found that in ME with a thin micro-engineered microsieve possessing highly uniform pores, $16 \%$ of the pores was active at $\Delta \mathrm{p}_{\mathrm{tm}} / \mathrm{p}_{\text {cap }}=3$. The fact that all the pores did not become active at the same critical pressure although they had the same diameter, Abrahamse et al. [20] explained by a pressure drop under the membrane as soon as oil phase flows through some pores, preventing other pores to become active. They found that the proportion of active pores increased linearly with increasing transmembrane pressure, which was similar to our results given in Fig. 4. The greater proportion of active pores at the same $\Delta \mathrm{p}_{\mathrm{tm}} / \mathrm{p}_{\text {cap }}$ ratio in their experiments is a consequence of much smaller membrane thickness.

The capillary pressure can be calculated from the Laplace equation:

$$
\mathrm{p}_{\text {cap }}=\frac{4 \gamma_{\infty} \cos \theta}{\mathrm{d}_{\mathrm{p}}}
$$


Adopting from Fig. 3 that the equilibrium interfacial tension $\gamma_{\infty}$ between the continuous and dispersed phase is $8 \times 10^{-3} \mathrm{~N} / \mathrm{m}$ and assuming that the contact angle $\theta$ between the dispersed phase and the membrane surface is equal to zero, one obtains $\mathrm{p}_{\text {cap }}=6.7 \mathrm{kPa}$ for $d_{p}=4.8 \times 10^{-6} \mathrm{~m}$, which is very close to $7 \mathrm{kPa}$ found experimentally (Fig. 4).

The influence of shear stress of the continuous phase at the membrane surface on droplet size distribution for the $4.8 \mu \mathrm{m}-\mathrm{SPG}$ membrane is shown in Figs. 5 and 6 . With increasing the wall shear stress from 1.3 to $30 \mathrm{~Pa}$, the droplet size distribution curve shifts to smaller droplet diameters and it becomes narrower and narrower. For the given pore size and experimental conditions, a monodispersed emulsion ( $\operatorname{span}=0.43$ ) was even produced at $\sigma_{\mathrm{w}}=0.37 \mathrm{~Pa}$, corresponding to laminar flow inside the membrane tube $\left(v_{c}=0.3 \mathrm{~m} / \mathrm{s}\right.$ and $\left.\operatorname{Re}_{\mathrm{c}}=1,700\right)$. Williams et al. [21] obtained a span value of 0.82 at the mean tube velocity of $\mathrm{v}_{\mathrm{c}}=0.6 \mathrm{~m} / \mathrm{s}$ in a semi-continuous preparation of cosmetic model emulsions with alumina membranes. Abrahamse et al. [20] obtained polydispersed O/W emulsions using the microengineered membrane at $\sigma_{\mathrm{w}}=0.62 \mathrm{~Pa}$. It was due to dropletdroplet interactions before detachment from the pore tips, caused by high dispersed phase flux of up to $2500 \mathrm{~kg} \mathrm{~m}^{-2} \mathrm{~h}^{-1}$. In our experiment at $\sigma_{\mathrm{w}}=0.37 \mathrm{~Pa}$, due to careful control of oil flux the steric hinderence of droplets did not occur and monodispersed emulsion was produced, although the surface porosity was much higher (0.53-0.60 for SPG membrane and 0.15 for the given microsieve).

The span of droplet size distribution linearly decreased with increasing $\sigma_{\mathrm{w}}$ up to 30 $\mathrm{Pa}$, and then increased with the further increase in $\sigma_{\mathrm{w}}$ (Fig. 6). The increase in the span as $\sigma_{\mathrm{w}}$ increased from 30 to $40 \mathrm{~Pa}$ was due to the formation of smaller droplets at $40 \mathrm{~Pa}$, while the maximum droplet size was the same at both $\sigma_{\mathrm{w}}$ values (Fig. 5). The broader droplet size distribution at $\sigma_{\mathrm{w}}=40$ Pa can be explained by: (a) partial droplet disruption 
outside the membrane tube caused by high recirculation rate $\left(\mathrm{v}_{\mathrm{c}}=3.5 \mathrm{~m} / \mathrm{s}\right)$ and/or (b) too intensive droplet deformation before detachment from the pore tips.

The influence of dispersed phase content on droplet size distribution during ME was little investigated in the literature. Fig. 7 demonstrates that at the small $\Delta \mathrm{p}_{\mathrm{tm}} / \mathrm{p}_{\text {cap }}$ ratios the droplet size distribution curve has a similar shape in the range of $\varphi$ between 1.2 and 20 vol. \%. The span of distribution, however, somewhat increased with increasing $\varphi$. It is interesting to note that the minimum droplet size decreased with increasing $\varphi$ (by 17 $\%$ for the $2.5-\mu \mathrm{m}$ membrane in the range of $1.2-16 \mathrm{vol}$. $\%$ and by $24 \%$ for the $6.6-\mu \mathrm{m}$ membrane in the range of $1.2-20 \mathrm{vol}$ \%). It could be the consequence of gradual activation of smaller pores. As shown in Fig 8, oil flux increased with time at the constant transmembrane pressure, reflecting the fact that more and more pores were simultaneously active in droplet formation during the operation. The same type of behaviour was found in ME with $\alpha$-alumina and zirconia membranes [22, 23]. It is reasonably to suggest that when $t \rightarrow 0$, only the largest pores are partially active, while the smallest ones are completely inactive. In the subsequent stage of operation, the smaller pores are gradually activated and as a result, minimum droplet size decreases. The pore activation till steady state is a slow process at the small $\Delta \mathrm{p}_{t m} / \mathrm{p}_{\text {cap }}$ ratio, so that for the conditions is in Fig. 8, the stationary state was not yet established after 5 hours of operation.

The droplet size distribution of $\mathrm{O} / \mathrm{W}$ and $\mathrm{W} / \mathrm{O} / \mathrm{W}$ emulsions prepared using the same $5 \mu \mathrm{m}$-SPG membrane is compared in Fig. 9. There is no significant difference in the shape of the size distribution curve of pure oil droplets of an $\mathrm{O} / \mathrm{W}$ emulsion and $\mathrm{W} / \mathrm{O}$ drops of $\mathrm{W} / \mathrm{O} / \mathrm{W}$ emulsion, if they are prepared under the same conditions. The inner water droplets produced using the microfluidizer ${ }^{\circledR}$ are highly polydispersed, while the 
outer drops prepared by ME are relatively uniform. With decreasing transmembrane pressure, the size distribution curve of W/O drops shifts to smaller diameters and exhibits a higher peak, which was also found for O/W emulsions (Fig. 3).

\subsection{Stability of prepared O/W emulsions}

The variation of droplet size distribution with time was investigated during stationary storage of samples in a glass cylinder at room temperature $\left(20-25^{\circ} \mathrm{C}\right)$. Due to relatively large mean droplet size in this study, the samples formed a dense creamed layer after only several hours of stationary storage, so that virtually over the whole storage time oil droplets were highly concentrated in a creamed layer. In spite of that, the droplets were stable and no appreciable change in the mean droplet size or the span of distribution was observed over 3 months, as shown in Fig. 10. The stability of oil droplets mainly depended on the initial uniformity, while mean droplet size was not an important factor. If the droplets in fresh samples were highly uniform, like in Fig. 11, the droplet size distribution did not change significantly even after 5 months. The micrographs shown in Fig. 12 indicate that the oil droplets are still uniform 1-2 months after preparation, irrespective of the mean droplet size. Asano and Sotoyama [18] have investigated the stability of O/W food emulsions prepared using MPG membranes. They found that after a month at room temperature the coefficient of variation of mean droplet size increased by $15,7,0$, and $4 \%$ for $1.1,2.9,4.5$, and $5.7-\mu \mathrm{m}$ membrane. In the present work, after 3 months the span of distribution did not change (Fig. 10) and after 159 days it increased only by $6 \%$ for $6.6-\mu$ m membrane. The similar type of behaviour was found for other pore sizes. 


\section{Conclusions}

$\mathrm{O} / \mathrm{W}$ and $\mathrm{W} / \mathrm{O} / \mathrm{W}$ emulsions with a narrow droplet size distribution can be prepared by SPG membrane emulsification over a wide range of membrane wall shear stress (0.37-40 Pa), dispersed phase content (up to 20 vol. \%) and transmembrane pressure (1.2-5.7 times larger than the capillary pressure). The span of droplet size distribution linearly decreased with increasing membrane wall shear stress up to $30 \mathrm{~Pa}$, and then increased with the further increase of shear stress. At the small $\Delta \mathrm{p}_{\mathrm{tm}} / \mathrm{p}_{\text {cap }}$ ratio, the droplet size distribution curve has a similar shape for dispersed phase contents up to 20 vol. \%. However, the minimum droplet size somewhat decreased with time, which was probably due to gradual activation of smaller pores. There is no significant difference in the size distribution curve of pure oil droplets of $\mathrm{O} / \mathrm{W}$ emulsions and $\mathrm{W} / \mathrm{O}$ drops of W/O/W emulsions, if they are both prepared under the same conditions. In spite of high creaming rate, the prepared $\mathrm{O} / \mathrm{W}$ emulsions were stable and no significant change in mean droplet size or droplet size distribution was observed during the storage time of several months.

\section{List of Symbols}

$d_{p} \quad$ mean pore size of membrane, $m$

$\mathrm{d}_{\text {drop }} \quad$ droplet diameter, $\mathrm{m}$

$\mathrm{d}_{3,2} \quad$ mean Sauter diameter, $\mathrm{m}$

$\mathrm{J} \quad$ instantaneous dispersed phase flux, $\mathrm{m} \mathrm{s}^{-1}$

$\mathrm{J}_{\mathrm{d}} \quad$ steady-state or final dispersed phase flux, $\mathrm{m} \mathrm{s}^{-1}$

$\mathrm{k} \quad$ proportion of simultaneously active pores, (-)

Pcap capillary pressure, $\mathrm{Pa}$ 
$\Delta \mathrm{p}_{\mathrm{tm}} \quad$ transmembrane pressure, $\mathrm{Pa}$

$\mathrm{Re}_{\mathrm{c}} \quad$ Reynolds number inside membrane tube, (-)

$\mathrm{t} \quad$ time, $\mathrm{s}$

$\mathrm{v}_{\mathrm{C}} \quad$ mean velocity of continuous phase inside membrane tube, $\mathrm{m} / \mathrm{s}$

$\sigma_{\mathrm{w}} \quad$ shear stress in continuous phase at membrane surface (wall shear stress), Pa

$\varphi \quad$ proportion of dispersed phase in emulsion, vol. \%

$\gamma_{\infty} \quad$ equilibrium interfacial tension between dispersed and continuous phase, $\mathrm{N} / \mathrm{m}$

$\gamma \quad$ dynamic interfacial tension between dispersed and continuous phase, $\mathrm{N} / \mathrm{m}$

$\theta \quad$ contact angle between dispersed phase and membrane surface, rad

\section{Acknowledgement.}

The authors wish to thank the Alexander von Humboldt Foundation, Bonn, Germany for the financial support of this work.

\section{References}

[1] T. Nakashima, M. Shimizu and M. Kukizaki, Membrane emulsification by microporous glass, in: Proceedings of the $2^{\text {nd }}$ International Conference on Inorganic Membranes, Montpellier, France, 1991.

[2] K. Suzuki, I. Shuto and Y. Hagura, Characteristics of the membrane emulsification method combined with preliminary emulsification for preparing corn oil-in-water emulsions, Food. Sci. Technol. Int., 2 (1986) 43. 
[3] S.M. Joscelyne and G. Trägårdh, Membrane emulsification - a literature review, J. Membr. Sci., 169 (2000) 107.

[4] M. Shimizu, K. Torigoe, I. Akazaki and T. Nakashima, Preparation of monodispersed solder microspheres by membrane emulsification, in: Proceedings of the $36^{\text {th }}$ SPG Forum, Miyazaki, Japan, 2001, 78.

[5] E. Toorisaka, H. Ono, K. Arimori, N. Kamiya, M. Goto, Hypoglycemic effect of surfactant-coated insulin solubilized in a novel solid-in-oil-in-water (S/O/W) emulsion, International Journal of Pharmaceutics, 252 (2003) 271-274.

[6] T. Nakashima, History of SPG technology and its recent advances, in: Proceedings of the $38^{\text {th }}$ SPG Forum, Miyazaki, Japan, 2002, 63.

[7] T. Nakashima, M. Shimizu and M. Kukizaki, Particle control of emulsion by membrane emulsification and its applications, Adv. Drug Deliv. Rev., 45 (2000) 47.

[8] K. Hosoya, K. Yoshizako, K. Kimata and N. Tanaka, Chromatographic properties of uniformly sized macroporous polymer particles prepared using SPG emulsification, Chromatography, 18 (1997) 226.

[9] S. Omi, K. Kaneka, A. Nakayama, K. Katami, T. Taguchi, M. Iso, M. Nagai and M.G.H. Ma, Application of porous microspheres prepared by SPG emulsification as immobilizing carriers of glucamylase (GluA), J. Appl. Polym. Sci., 65 (1997) 2655.

[10] Y.K. Ha, H.S. Song, H.J. Lee and J.H. Kim, Preparation of core particles for toner application by membrane emulsification, Colloid. Surface. A, 162 (2000) 289. 
[11] S. Higashi, M. Shimizu, T. Nakashima, K. Iwata, F. Uchiyama, S. Taneto, S. Tamura and T. Setoguchi, Arterial injection chemotherapy for hepatocellular carcinoma using monodispersed poppy seed oil microdroplets containing fine aqueous vesicles of epirubicin - initial medical application of a membrane emulsification technique, Cancer, 75 (1995) 1245.

[12] S. Okonogi, R. Kato, Y. Asano, H. Yuguchi, R. Kumazawa, K. Sotoyama, K. Takahashi and M. Fujimoto, Methods for producing emulsions, low-fat spread and oil-in-water-in-oil type spread, U.S. Patent 5,279,847, 1994.

[13] T. Nakashima and M. Shimizu, Porous glass from calcium alumino boro-silicate glass, Ceramics Japan, 21 (1986) 408.

[14] G.T. Vladisavljević, U. Lambrich, M. Nakajima and H. Schubert, Production of $\mathrm{O} / \mathrm{W}$ emulsions using SPG membranes, ceramic $\alpha-\mathrm{Al}_{2} \mathrm{O}_{3}$ membranes, microfluidizer and a microchannel plate - a comparative study, Colloid. Surface. A, submitted for application.

[15] M. Kukizaki, T. Nakashima T. and M. Shimizu, Preparation of new asymmetric type of porous glass and effect of its structure on microfiltration, Membrane, 27 (2002) 324.

[16] I. Scherze, K. Marzilger and G. Muschiolik, Emulsification using micro porous glass (MPG): surface behaviour of milk proteins, Colloids and Surfaces B, 12 (1999) 213.

[17] Y. Asano and K. Sotoyama, Viscosity change in oil/water food emulsions prepared using a membrane emulsification system, Food Chemistry, 66 (1999) 327. 
[18] G.T. Vladisavljević and H. Schubert, Preparation and analysis of oil-in-water emulsions with a narrow droplet size distribution using Shirasu-porous-glass (SPG) membranes, Desalination, 144 (2002) 167.

[19] M. Stang, H. Karbstein and H. Schubert, Adsorption kinetics of emulsifiers at oilwater interfaces and their effect on mechanical emulsification, Chem. Eng. Process., 33 (1994) 307.

[20] A.J. Abrahamse, R. van Lierop, R.G.M. van der Sman, A. van der Padt and R.M. Boom, Analysis of droplet formation and interactions during cross-flow membrane emulsification, J. Membr. Sci., 204 (2002) 125.

[21] R.A. Williams, S.J. Peng, D.A. Wheeler, N.C. Morley, D. Taylor, M. Whalley and D.W. Houldsworth, Controlled production of emulsions using a crossflow membrane, Chem. Eng. Res. Des., 76A (1998) 902.

[22] S.M. Joscelyne and G. Trägårdh, Food emulsions using membrane emulsification: conditions for producing small droplets, J. Food Eng., 39 (1999) 59.

[23] V. Schröder, Herstellen von Öl-in-Wasser-Emulsionen mit mikroporösen Membranen, Ph.D. thesis, University of Karlsruhe (T.H.), Germany, 1999. 


\section{FIGURE CAPTIONS}

Figure 1. Schematic diagram of the preparation of multiple $\mathrm{W} / \mathrm{O} / \mathrm{W}$ emulsion using SPG membrane.

Figure 2. The dynamic interfacial tension of Tween 80 solution at two different concentrations measured by the bursting membrane method.

Figure 3. Influence of transmembrane pressure on the droplet size distribution.

Figure 4. Influence of transmembrane pressure on the dispersed phase flux and the percentage of active pores.

Figure 5. Influence of shear stress at the membrane surface on the droplet size distribution.

Figure 6. Influence of shear stress at the membrane surface on the span of the droplet size distribution.

Figure 7. Influence of dispersed phase content, i.e. emulsification time on the droplet size distribution.

Figure 8. The variation of dispersed phase flux with time for two SPG membranes. 
Figure 9. The comparison of droplet size distribution for multiple $\mathrm{W} / \mathrm{O} / \mathrm{W}$ emulsion (inner and outer droplets) and O/W emulsion.

Figure 10. The variation of the mean droplet size and the span of distribution with time during stationary storage of $\mathrm{O} / \mathrm{W}$ emulsions prepared with different SPG membranes.

Figure 11. Influence of storage time on the droplet size distribution for $\mathrm{O} / \mathrm{W}$ emulsions produced using two different SPG membranes.

Figure 12. Photomicrographs of the emulsion droplets prepared by utilizing SPG membranes of different mean pore sizes: (a) $d_{p}=6.6 \mu \mathrm{m}, d_{3,2}=24 \mu \mathrm{m}, 61$ day-old emulsion; (b) $d_{p}=4.8 \mu \mathrm{m}, \mathrm{d}_{3,2}=17.5 \mu \mathrm{m}$, fresh emulsion; (c) $\mathrm{d}_{\mathrm{p}}=$ $1.4 \mu \mathrm{m}, \mathrm{d}_{3,2}=4.6 \mu \mathrm{m}, 48$-day-old emulsion. The same magnification was used for all photographs. 


\section{FIGURES}

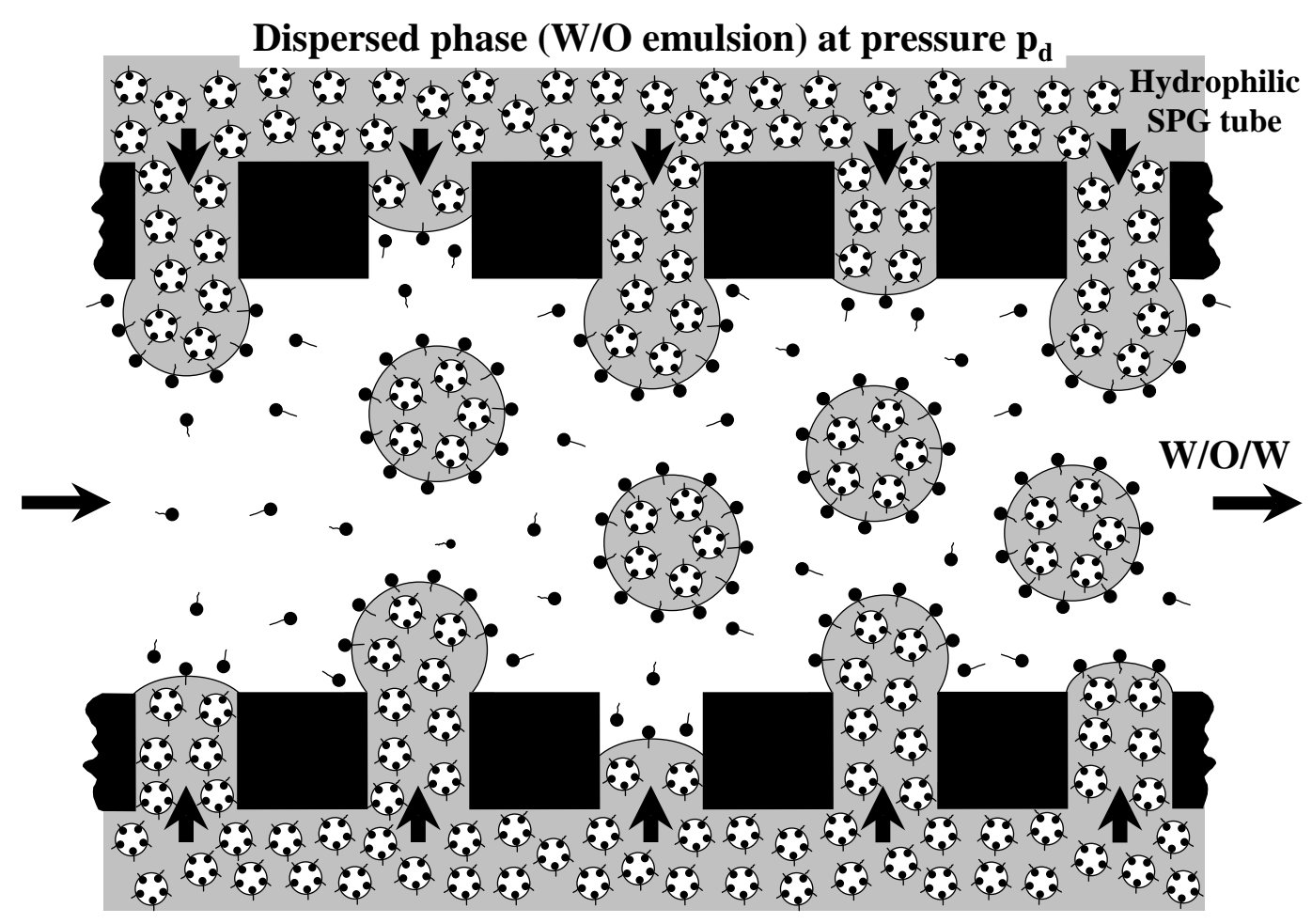

Fig. 1, Vladisavljevic et al. 


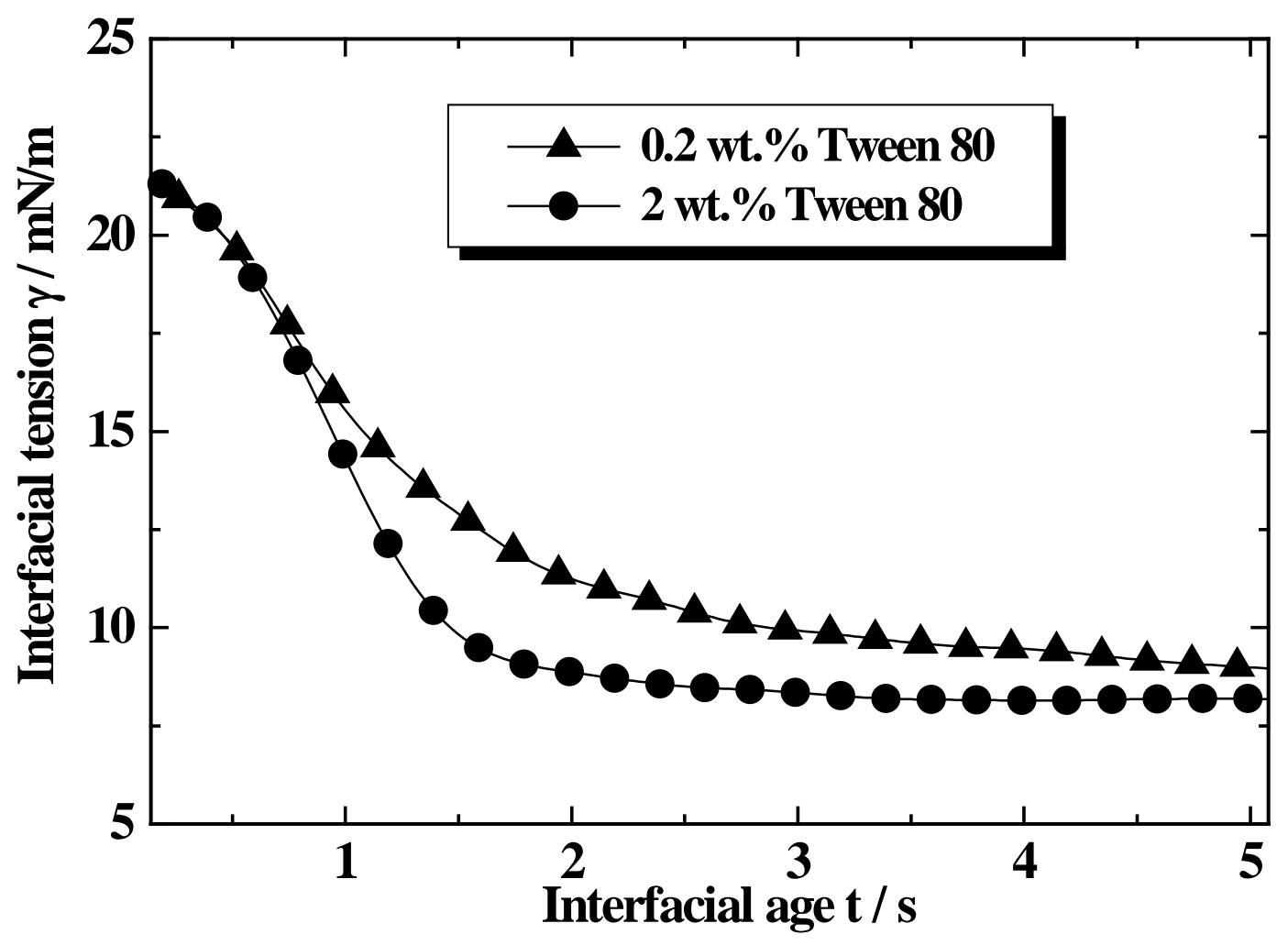

Fig. 2, Vladisavljevic et al. 


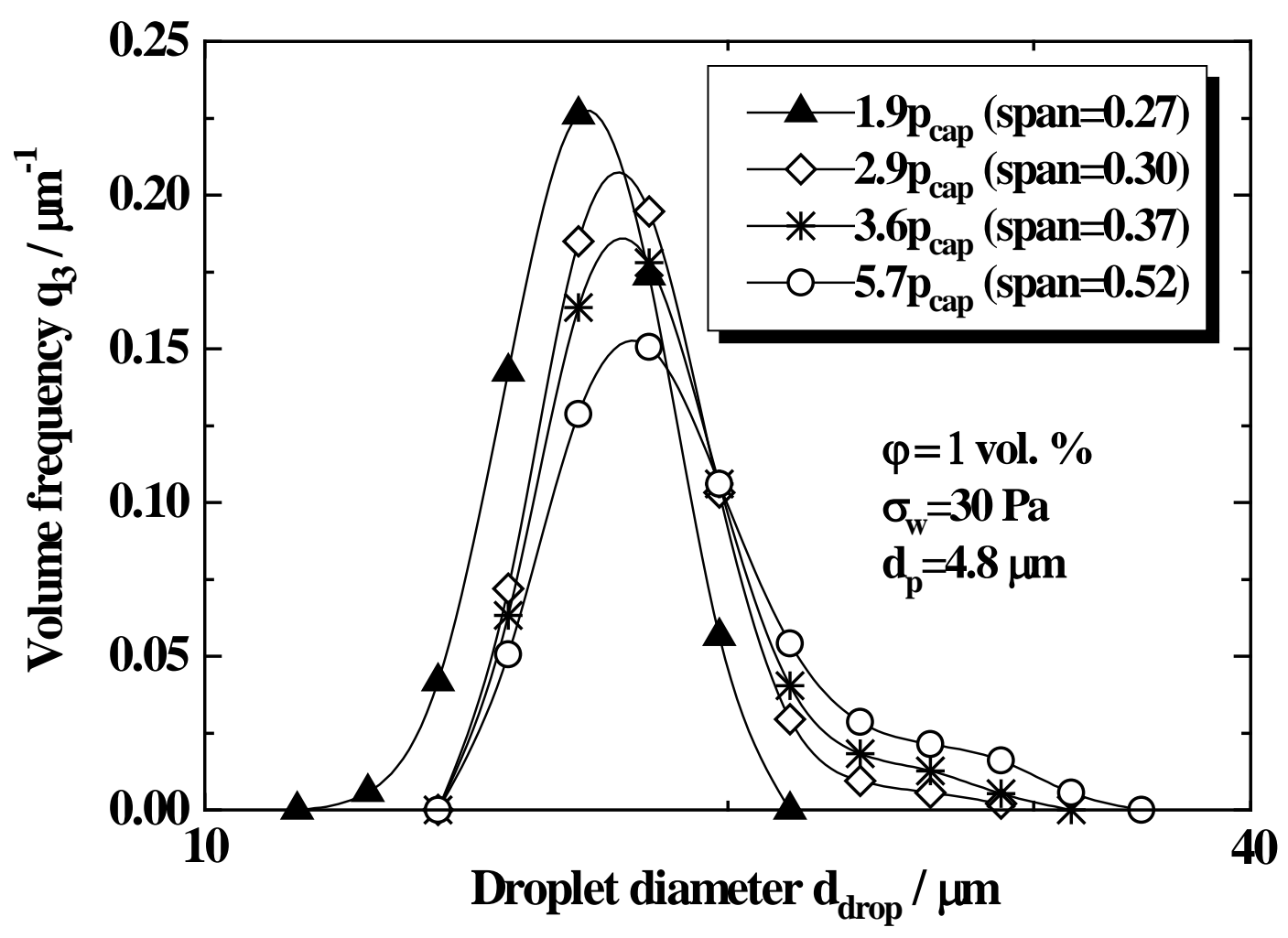

Fig. 3, Vladisavljevic et al. 


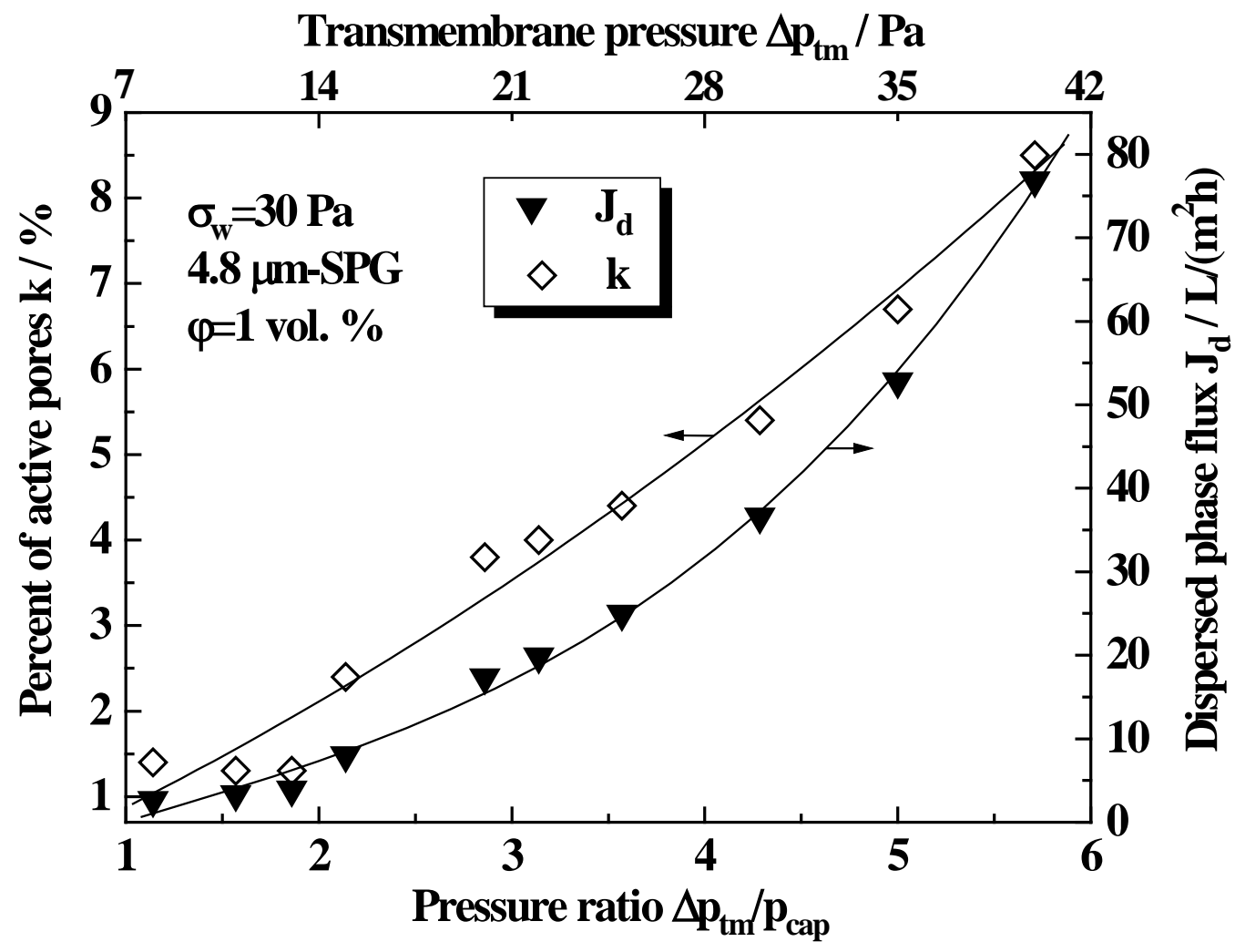

Fig. 4, Vladisavljevic et al. 


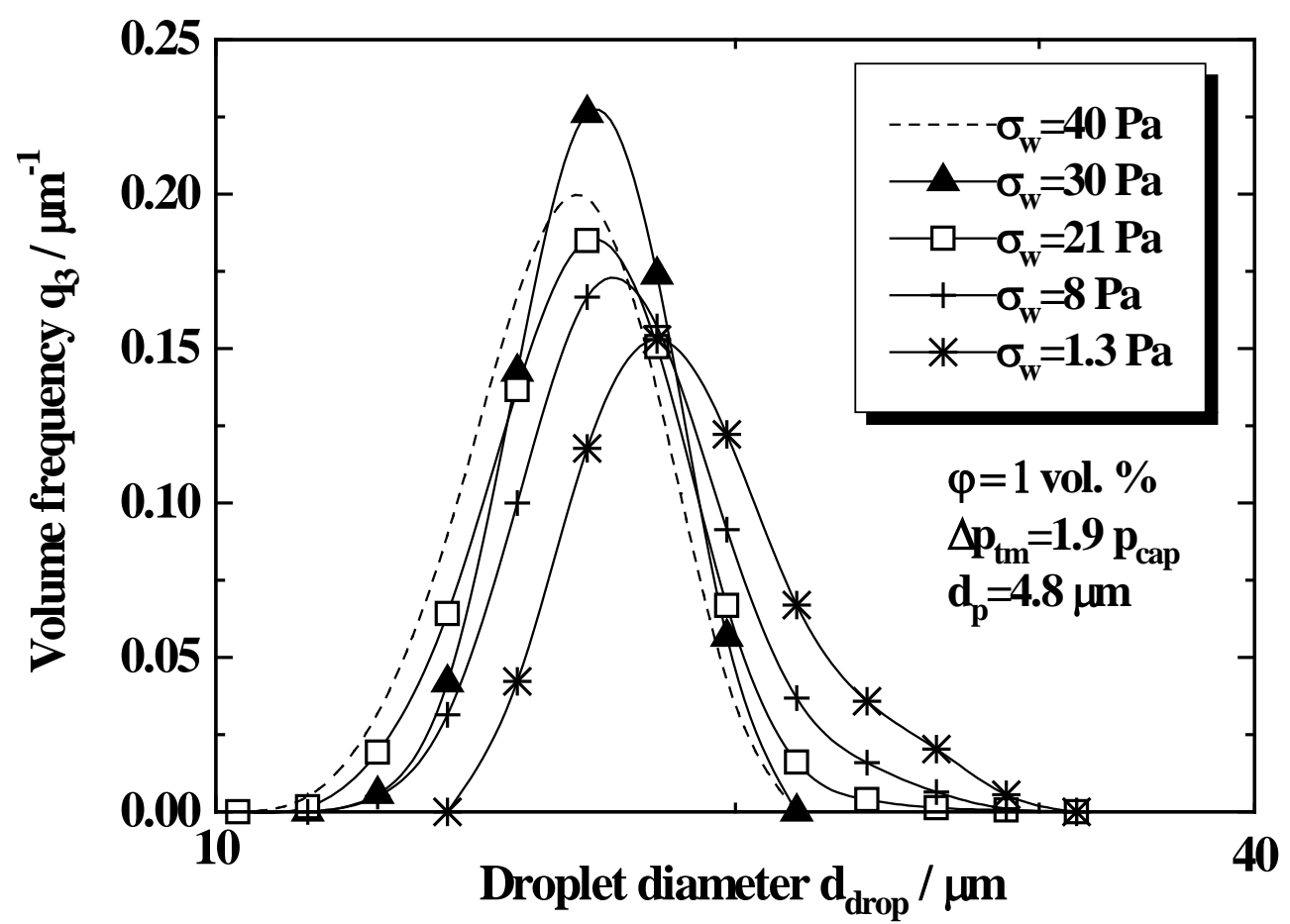

Fig. 5, Vladisavljevic et al. 


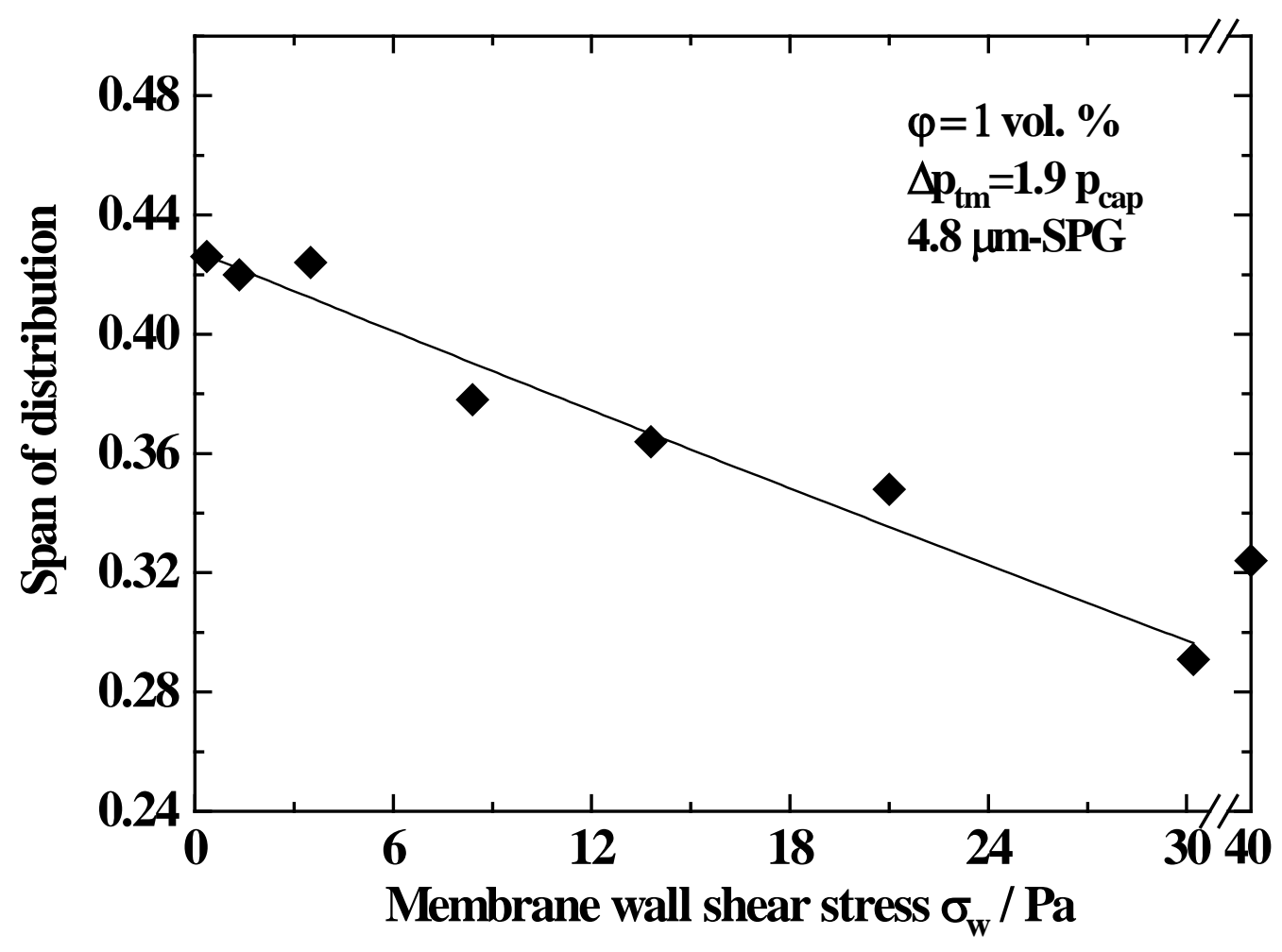

Fig. 6, Vladisavljevic et al. 


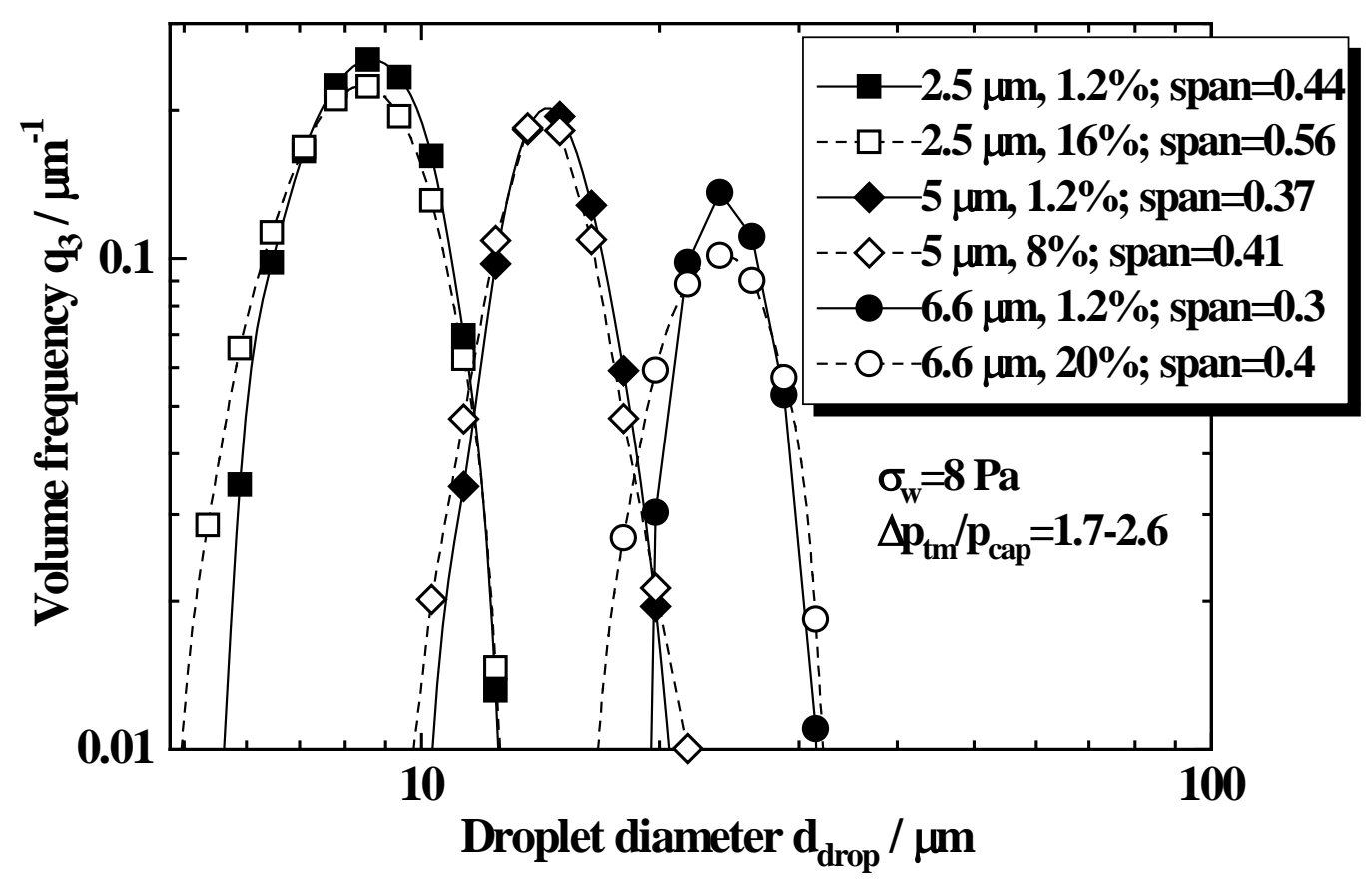

Fig. 7, Vladisavljevic et al. 


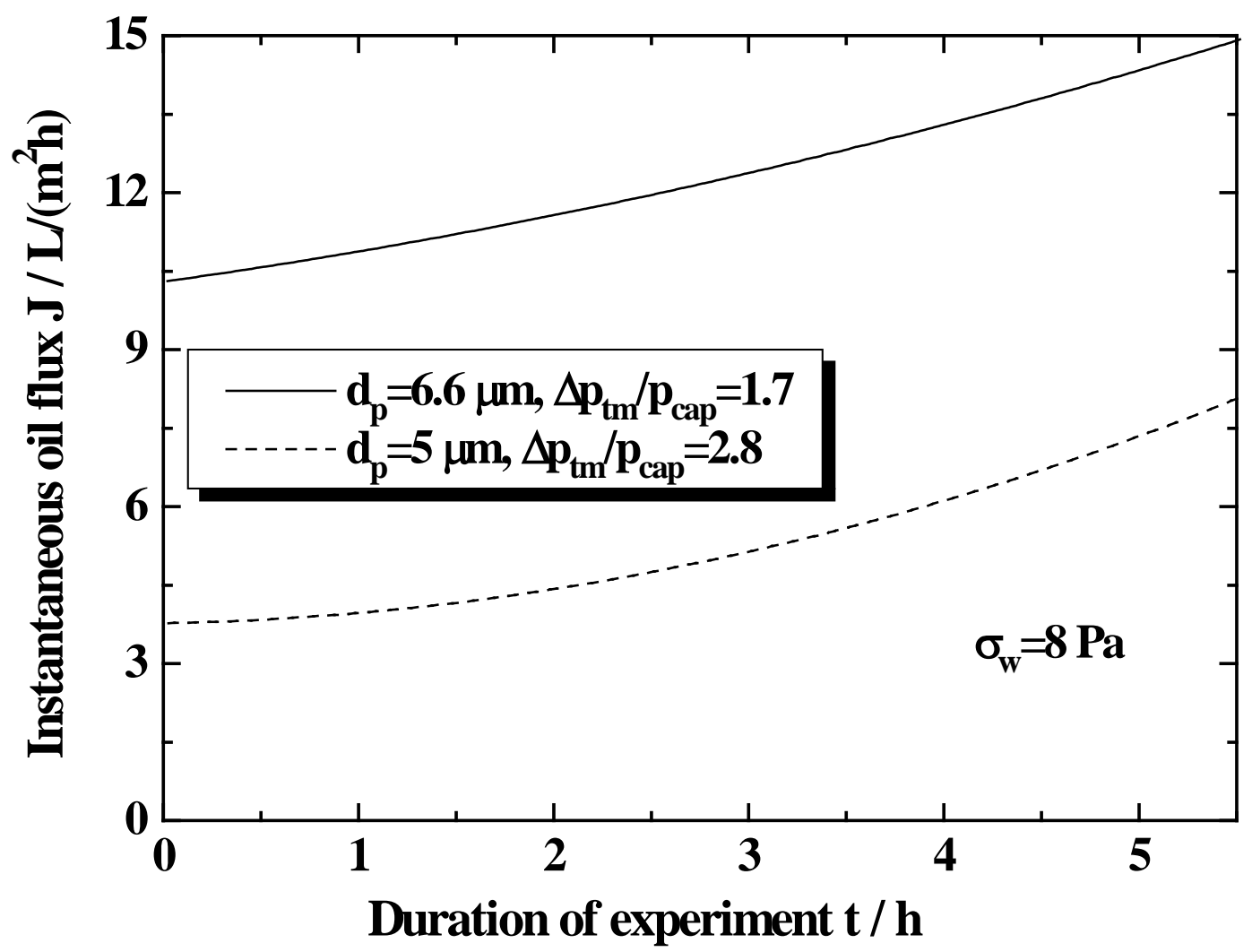

Fig. 8, Vladisavljevic et al. 


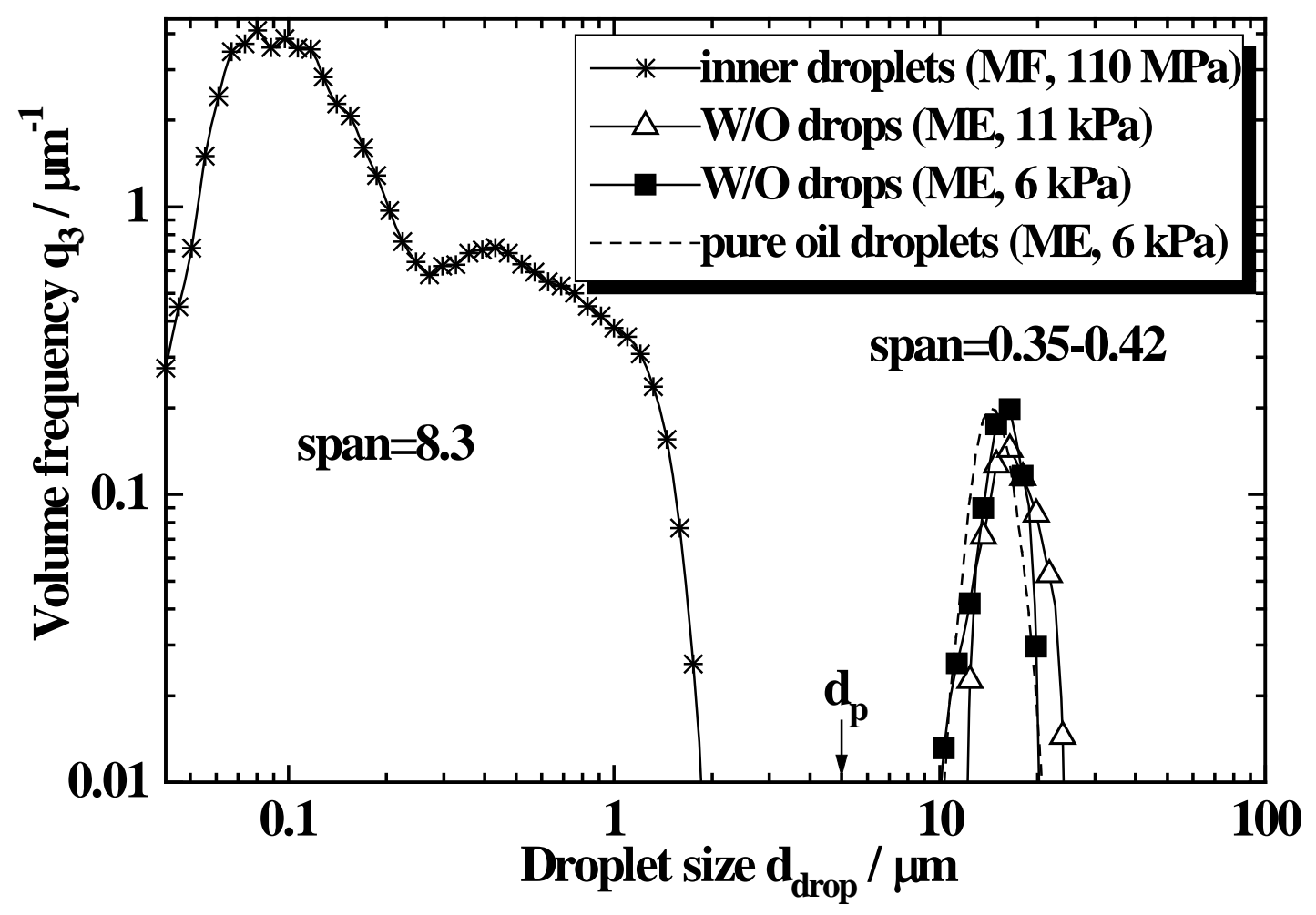

Fig. 9, Vladisavljevic et al. 


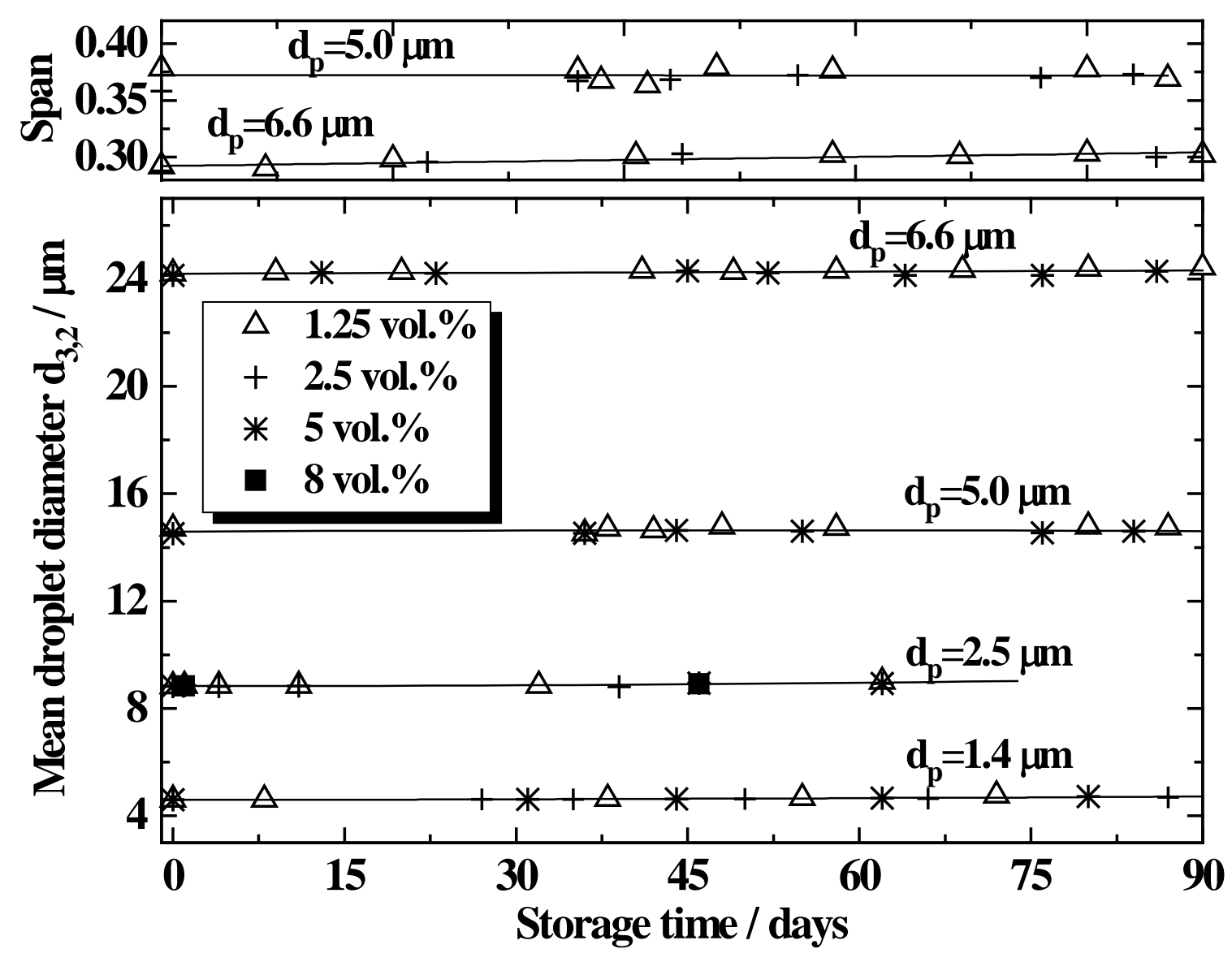

Fig. 10, Vladisavljevic et al. 


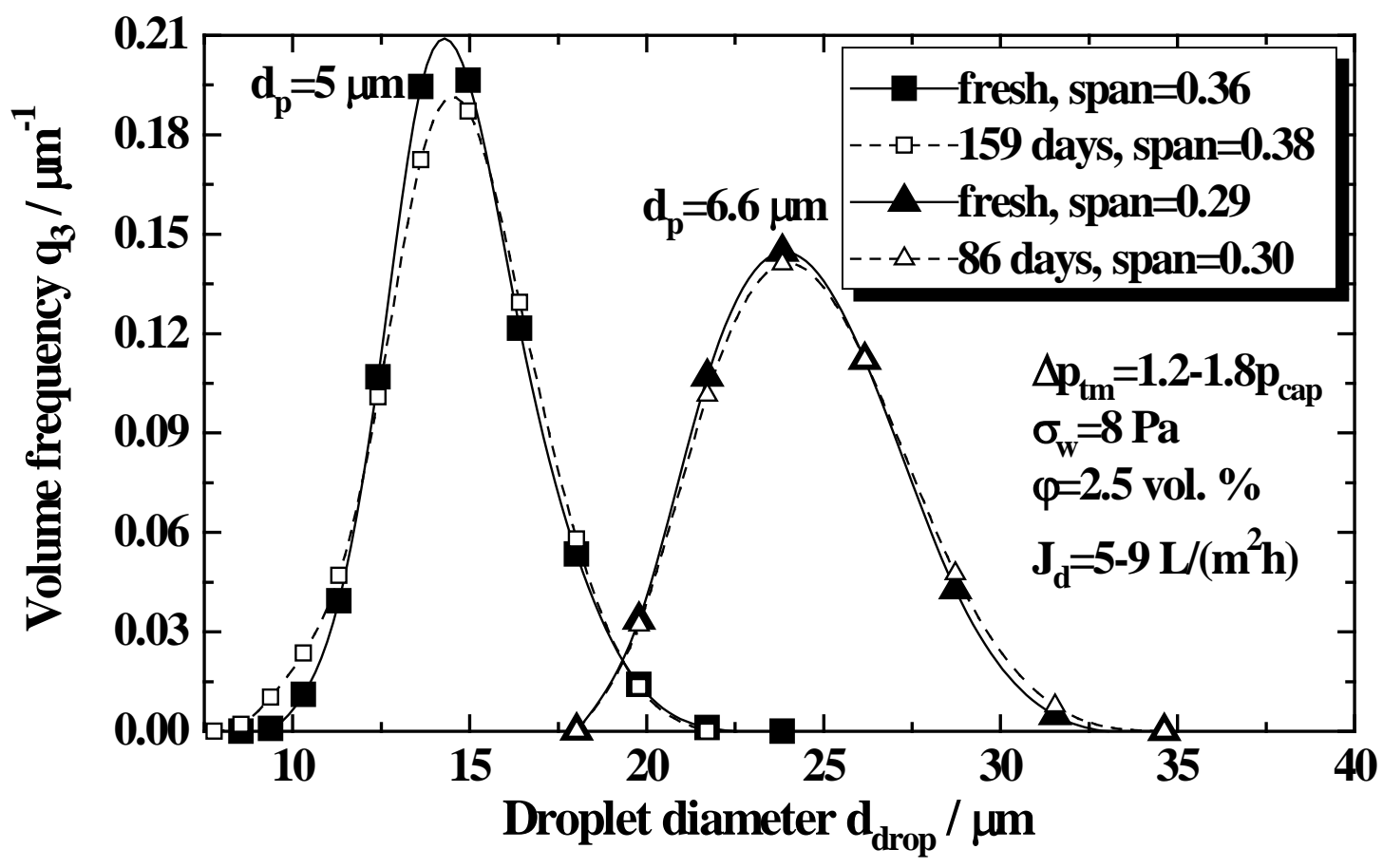

Fig. 11, Vladisavljevic et al. 


\section{$\begin{array}{lll}\text { (a) } 6.6 \mu \mathrm{m} \text {-membrane } & \text { (b) } 4.8 \mu \mathrm{m} \text {-membrane } & \text { (c) } 1.4 \mu \mathrm{m} \text {-membrane }\end{array}$}

Fig. 12, Vladisavljevic et al. 